\title{
Influence of moderate heat pre-treatments on physical and chemical characteristics of kiwifruit slices
}

\author{
Sara Beirão-da-Costa $\cdot$ Ana Steiner $\cdot$ \\ Lúcia Correia · Eduardo Leitão · José Empis • \\ Margarida Moldão-Martins
}

Received: 20 October 2006 / Revised: 2 January 2007 / Accepted: 6 January 2007 / Published online: 14 February 2007

(C) Springer-Verlag 2007

\begin{abstract}
The effect of mild heat treatments, applied to whole kiwifruit, on physical characteristics and chemical composition of minimally processed fruit was studied. Fruits were subjected to heat treatments at $45^{\circ} \mathrm{C}$ for 25 and $75 \mathrm{~min}$, cooled for $24 \mathrm{~h}$, minimally processed and stored at $4{ }^{\circ} \mathrm{C}$ for 12 days. Heat-treated fruits showed increased respiration rates in the first 2 days of storage. Samples colour was marginally affected either by heat treatments or by minimal processing. The application of heat treatments leads to an increment of slices firmness due to cross linking between demethylated galacturonic acid chains and endogenous calcium. An increment in sucrose, Lmalic, citric, quinic and ascorbic acids was observed as a consequence of applied heat treatments. Heat treatment at $45^{\circ} \mathrm{C}$ for $25 \mathrm{~min}$ applied to whole fruits allows quality retention of minimally processed fruit during 9 days at $4{ }^{\circ} \mathrm{C}$.
\end{abstract}

Keywords Kiwifruit - Minimal processing · Composition $\cdot$ Moderate heat treatments

\footnotetext{
S. Beirão-da-Costa $(\bowtie) \cdot$ A. Steiner $\cdot$ L. Correia $\cdot$ E. Leitão M. Moldão-Martins

CEAA, Instituto Superior de Agronomia,

Technical University of Lisbon,

Tapada da Ajuda, 1340-017 Lisboa,

Portugal

e-mail: sarabeirao@isa.utl.pt

J. Empis

IBB, Instituto Superior Técnico,

Technical University of Lisbon,

Av. Rovisco Pais, 1049-001 Lisboa, Portugal
}

\section{Introduction}

The most important motivation for purchasing minimally processed products relates to convenience [1] but the health benefits associated with the consumption of fruits and vegetables have led to a growing attention to this kind of products $[2,3]$.

Convenience and quality are the two aims difficult to harmonize because minimal processing operations lead to physiological and biochemical changes typical of the senescence process such as increased respiration, ethylene production and loss of membrane integrity [3-5].

Minimal processed kiwifruit undergoes several deteriorative reactions leading to loss of firmness, increased respiration and ethylene production rates, mass and flavour loss [6-8]. Some efforts had been made in order to get a better preservation of the sliced fruit, such as application of 1-methylcyclopropene (1-MCP) prior to cutting, packaging in non-conventional modified atmosphere with argon and nitrous oxide [9], application of volatile compounds such as methyl jasmonate, ethanol and other alcohols [10], treatments with hydrogen peroxide, calcium lactate and controlled atmosphere packaging [11].

The effects of mild heat treatments on the postharvest physiology of fruits and vegetables were already discussed [12-16]. This kind of treatments was effective in quality maintenance of fresh cut cantaloupe melon $[4,17,18]$, apples [19] and mango [20].

Moderate heat treatments applied to whole kiwifruit were found to be an interesting methodology able to better preserve minimally processed fruit slices [12] but the underlying mechanisms remain somewhat unknown. The objective of the present work was to 
Table 1 Physical and chemical characterization of raw material

\begin{tabular}{ll}
\hline Firmness $\left(\mathrm{N} / \mathrm{mm}^{2}\right)$ & $0.052 \pm 0.0025$ \\
Colour (outer pericarp/white core) & \\
$\mathrm{L}^{*}$ & $45.30 \pm 1.254 / 67.93 \pm 1.047$ \\
$c$ & $20.14 \pm 1.001 / 23.27 \pm 0.718$ \\
$H$ & $116.77 \pm 0.431 / 108.38 \pm 0.312$ \\
Total soluble solids & 12.8 \\
PH & 3.5 \\
Calcium $(\mathrm{mg} / 100 \mathrm{~g}$ fw) & $33.97 \pm 1.212$ \\
Sugars $(\mathrm{g} / 100 \mathrm{~g} \mathrm{dw})$ & \\
Sucrose & $4.28 \pm 0.133$ \\
Fructose & $23.91 \pm 2.846$ \\
Glucose & $17.45 \pm 1.812$ \\
Acids $(\mathrm{g} / 100 \mathrm{~g} \mathrm{dw})$ & \\
Malic & $0.14 \pm 0.003$ \\
Citric & $2.42 \pm 0.016$ \\
Quinic & $3.09 \pm 0.063$ \\
L-Ascorbic & $0.17 \pm 0.003$
\end{tabular}

Mean values \pm standard error. Firmness $n=30$; colour $n=20$; other parameters $n=3$

understand the physical and chemical changes involved in minimally processed kiwifruit previous subjected to moderate heat treatments.

\section{Materials and methods}

\section{Materials}

Kiwifruits [Actinidia deliciosa (A Chev) Liang et Ferguson var deliciosa cv Hayward] were purchased at a local market. Fruits selected by uniform size and the absence of visual wounds was stored under refrigeration $\left(4{ }^{\circ} \mathrm{C}\right)$ prior to pre-treatments and/or minimal processing. Physical and chemical fruit characteristics are summarized in Table 1.

As it was apparent from previous works [12] that maturity stage has relevance in the treatments' efficiency, so total soluble solids and $\mathrm{pH}$ were measured for the raw material.

Despite the low firmness value, total soluble solids and $\mathrm{pH}$ denote that fruits were at a ripe stage, adequate for consumption (TSS $\geq 12.5 \%$ ). The lowest firmness value may be indicative of early harvested fruits followed by storage, because as [21] state, late harvested kiwifruit retains their flesh firmness during storage better than early harvested fruit.

\section{Methods}

\section{Heat treatments}

Whole kiwifruits were subjected to immersion heat treatments at $45^{\circ} \mathrm{C}$ for $25 \mathrm{~min}$ and for $75 \mathrm{~min}$ [12], rapidly cooled in a cold chamber $\left(4^{\circ} \mathrm{C}\right)$ and kept under cold storage $\left(4^{\circ} \mathrm{C}\right)$ for $24 \mathrm{~h}$. Non-treated fruits were used as control.

\section{Minimal processing}

Heat-treated and control fruits were hand peeled, washed in a cold sodium hypochlorite solution $\left(125 \mathrm{mg} / \mathrm{L}\right.$ free of $\mathrm{Cl}^{-}$, at $\mathrm{pH}$ 6), gently dried with a blotting paper and cut into slices $(\approx 1.5 \mathrm{~cm}$ thickness) with sharpened knives. Slices from different fruits were randomly distributed and each $250 \mathrm{~g}$ packed in lowdensity polyethylene and vinylidene chloride bags [3,000-4,000 and 11,000-15,000 (mL/m²/24 h/atm) permeability to $\mathrm{O}_{2}$ and $\mathrm{CO}_{2}$, respectively], and stored at $4{ }^{\circ} \mathrm{C}$. At each date of analysis three packages per sample were evaluated.

\section{Analytical procedures}

During cold storage, samples were analysed for package atmosphere composition, colour, firmness, free and linked calcium, sugars, acids and pectic polymers.

Sensory analysis was performed by a ten element trained panel, concomitantly with those objective determinations.

Atmosphere composition. Headspace gas samples were taken with a hypodermic needle through an adhesive septum previously fixed on the bags and analysed using a checkmate $9,900 \quad \mathrm{O}_{2} / \mathrm{CO}_{2}$ gas analyser (PBIDansensor, Denmark).

Colour. The colour of kiwifruit slices was evaluated both on outer pericarp and on inner white core. Measurements, made with a Minolta CR300 colorimeter, were taken by $\mathrm{L}^{*}, \mathrm{a}^{*}, \mathrm{~b}^{*}$ (CIE) parameters. Hue angle $\left(h^{\circ}\right)$ and chroma $(c)$ were calculated [22]. Results were the mean of 20 measures on each section of fruit slices.

Firmness. Firmness was evaluated by performing a puncture test on flesh of kiwifruit slices using a TA-XT2 texture analyser from Stable Micro Systems, equipped with a $25 \mathrm{~kg}$ load cell. Firmness measurements were taken as the medium force attained in a puncture at $4 \mathrm{~mm}$ distance, at $1 \mathrm{~mm} / \mathrm{s}$ with a $4 \mathrm{~mm}$ diameter stainless steel probe. Results were the mean of 30 measures for every sample. As firmness is the critical parameter in minimally processed kiwifruit's shelf life, this parameters' analysis was extended for 12 days of storage.

Calcium. Calcium analysis was performed on the fruit's outer pericarp, without seeds, using the method described by [17], slightly modified. About $2 \mathrm{~g}$ of kiwifruit cut in small cubes and $20 \mathrm{~mL}$ of cold deionized water were homogenized. About $5 \mathrm{~mL}$ of water used to 
wash apparatus was added. The mixture was stirred at low speed for $1 \mathrm{~h}$. About $5 \mathrm{~mL}$ of rinse water used was added to the homogenate before centrifugation at $20,000 \mathrm{~g}$ for $1 \mathrm{~h}$, at $4{ }^{\circ} \mathrm{C}$ using a Hermle $\mathrm{Z} 383 \mathrm{~K}$ (Germany). Samples were filtered through the Whatman 541 ashless filter paper. About $30 \mathrm{~mL}$ of filtrate was added of $30 \mathrm{~mL}$ of $3 \mathrm{~mol} / \mathrm{L} \mathrm{HCl}$ to determine free calcium. The insoluble material was incinerated with the filter paper at $550{ }^{\circ} \mathrm{C}$ for $24 \mathrm{~h}$ and re-suspended in $10 \mathrm{~mL}$ of $3 \mathrm{~mol} / \mathrm{L} \mathrm{HCl}$ and $40 \mathrm{~mL}$ of deionized water. Strontium chloride was added to control ionization interferences. Calcium levels were determined at $422.7 \mathrm{~nm}$ using an atomic absorption spectrophotometer equipped with an air-acetylene flame.

Sugars and organic acids. Sugars and organic acids were extracted and analysed by HPLC according to the method described by [23]. About $10 \mathrm{~g}$ of kiwi was homogenized in $25 \mathrm{~mL}$ distilled water and the sample clarified by centrifugation at 20,000 $\mathrm{g}$ for $20 \mathrm{~min}$. The pellet was washed with $25 \mathrm{~mL}$ distilled water, centrifuged again, and the supernatants collected and pooled. Samples were filtered through $0.45 \mu \mathrm{m}$ filters prior to HPLC analysis.

Sugar content was evaluated by an HPLC system consisting of a 125 Beckman pump, a differential refractometer model 401, a R460 Waters detector and a Waters 745 integrator. A Sugar Pak 1 column from Waters was used. The mobile phase was $50 \mathrm{mg} / \mathrm{L} \mathrm{cal}-$ cium EDTA solution and the flow rate $0.5 \mathrm{~mL} / \mathrm{min}$ at $90{ }^{\circ} \mathrm{C}$. The sample volume injected was $20 \mu \mathrm{L}$.

For the determination of organic acids a Beckman system Gold chromatograph was used. The HPLC system consisted of a 126 Beckman pump, a diode array detector model 168, operated by Gold 8.10 software. An Aminex HPX-87H column from Biorad was used. The mobile phase consisted of $5 \mathrm{mmol} / \mathrm{L}$ sulphuric

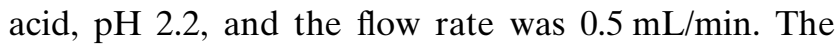
sample volume injected was $20 \mu \mathrm{L}$ and the detection was at $214 \mathrm{~nm}$.

Ascorbic acid was extracted according to a method described in [24]. About $50 \mathrm{~g}$ of kiwifruit was homogenized with $50 \mathrm{~mL}$ of metaphosphoric acid, during $15 \mathrm{~min}$. Then, another $50 \mathrm{~mL}$ of metaphosphoric acid were added. The slurry was filtered using the Whatman 42 filter paper. The filtrate was filtered again through $0.45 \mu \mathrm{m}$ filters prior to HPLC analysis. Ascorbic acid content was determined as referred for organic acids.

Pectic polymers. Pectin extraction/determination was performed according to [25]. Pectins were extracted from the alcohol insoluble residue (AIR) obtained homogenizing $20 \mathrm{~g}$ of fruit with $100 \mathrm{~mL}$ of boiling absolute ethanol. The homogenate was vacuum filtered, the residue washed with $80 \%$ ethanol until discolouration and the residue was dried at $35^{\circ} \mathrm{C} \pm 2{ }^{\circ} \mathrm{C}$.

About $100 \mathrm{mg}$ of AIR was homogenized with $50 \mathrm{~mL}$ of distilled water and stirred for $30 \mathrm{~min}$. The mixture was centrifuged at $15,000 \mathrm{~g}$ for $15 \mathrm{~min}$, the pellet resuspended in $50 \mathrm{~mL}$ of distilled water, stirred and centrifuged again. These procedures were repeated twice. The three supernatants were pooled and represent the water-soluble fraction (WSF). The pellet was resuspended in $50 \mathrm{~mL}$ of $0.05 \mathrm{~mol} / \mathrm{L} \mathrm{HCL}$ and incubated for $30 \mathrm{~min}$ at $98^{\circ} \mathrm{C}$ under reflux. All extractions were performed in triplicate.

Uronic acid concentrations were estimated by the $m$-hydroxydiphenyl method using galacturonic acid as standard [25].

Sensory analysis. Sensory evaluation of minimally processed kiwi samples was conducted in the sensory laboratory of the Department of Food Science and Technology, ISA/UTL. The sensory evaluation was performed by a total of ten trained judges (food engineering students and staff). All of them were nonsmokers and their age ranged from 25 to 63 years old. The room, at $20^{\circ} \mathrm{C}$, was equipped with seven isolated sensory booths. The tasting sessions occurred in the period from 10.00 AM to12.30 PM. Panellists performed a descriptive test and were asked to analyse the samples' colour, typical aroma, untypical aroma, typical taste and firmness, in a scale of five points. Those descriptors were selected in previous trials.

Statistics. Analysis of variance was applied to the results, as well as a mean comparison test (Fisher LSD), to analyse differences between treatments along storage time. Principal component analysis was also performed. "Statistica" v. 6.1 software from Statsoft, Inc., was used.

\section{Results and discussion}

Figure 1 shows the evolution of $\mathrm{CO}_{2}$ concentration in the headspace of minimally processed kiwifruit packages along the storage period. The analysis of atmosphere composition inside the packages during 9 days of storage revealed that minimal processing operations led to an enhancement of respiration rate with an accumulation of $\mathrm{CO}_{2}$ inside packaging of all samples, producing a modified atmosphere. Agar et al. [8] reported that kiwifruit slices had doubled their $\mathrm{CO}_{2}$ production rates of whole fruit few hours after peeling and slicing operations at $20^{\circ} \mathrm{C}$ and within 1 to 3 days at $2{ }^{\circ} \mathrm{C}$. Samples previously subjected to heat treatments exhibit a higher accumulation in the first 2 days of storage, 17 and $14 \%$ for treatments during 25 and $75 \mathrm{~min}$, 
Table 2 Colour of minimally processed kiwifruits' outer pericarp during storage

\begin{tabular}{|c|c|c|c|c|c|c|c|c|c|}
\hline \multirow{2}{*}{$\begin{array}{l}\text { Storage } \\
\text { time (day) }\end{array}$} & \multicolumn{3}{|c|}{$45^{\circ} \mathrm{C} / 25 \mathrm{~min}$} & \multicolumn{3}{|c|}{$45^{\circ} \mathrm{C} / 75 \mathrm{~min}$} & \multicolumn{3}{|l|}{ Control } \\
\hline & $\mathrm{L}$ & $c$ & $h$ & $\mathrm{~L}$ & $c$ & $h$ & $\mathrm{~L}$ & $c$ & $h$ \\
\hline 0 & $43.18^{\mathrm{ab}}$ & $19.00^{\mathrm{ab}}$ & $117.91^{\mathrm{a}}$ & $40.38^{\mathrm{bc}}$ & $15.94^{\mathrm{bc}}$ & $113.09^{\mathrm{abcd}}$ & $45.30^{\mathrm{a}}$ & $20.14^{\mathrm{a}}$ & $116.77^{\mathrm{ab}}$ \\
\hline 2 & $37.53^{\mathrm{cd}}$ & $12.00^{\text {cde }}$ & $110.70^{\text {cde }}$ & $36.00^{\mathrm{d}}$ & $13.42^{\text {cdef }}$ & $115.00^{\mathrm{abc}}$ & $40.19^{\mathrm{bc}}$ & $14.17^{\mathrm{cd}}$ & $110.70^{\text {cde }}$ \\
\hline 5 & $37.69^{\mathrm{cd}}$ & $10.86^{\text {def }}$ & $112.11^{\text {bcde }}$ & $37.56^{\mathrm{cd}}$ & $10.61^{\mathrm{f}}$ & $107.96^{\mathrm{e}}$ & $38.71^{\mathrm{cd}}$ & $12.83^{\mathrm{cdef}}$ & $109.01^{\mathrm{de}}$ \\
\hline 7 & $38.38^{\mathrm{cd}}$ & $13.91^{\mathrm{ef}}$ & $112.88^{\mathrm{bcd}}$ & $37.04^{\mathrm{d}}$ & $11.60^{\mathrm{def}}$ & $112.01^{\text {bcde }}$ & $40.29^{b c}$ & $12.32^{\mathrm{def}}$ & $109.60^{\mathrm{de}}$ \\
\hline 9 & $38.38^{\mathrm{cd}}$ & $10.42^{\mathrm{f}}$ & $107.48^{\mathrm{e}}$ & $37.31^{\mathrm{cd}}$ & $11.47^{\mathrm{def}}$ & $110.66^{\mathrm{cde}}$ & $37.81^{\mathrm{cd}}$ & $12.94^{\text {cdef }}$ & $110.94^{\text {cde }}$ \\
\hline
\end{tabular}

For each colour parameter values followed by the same lowercase letter are not significantly different at $P<0.01$, Fisher LSD test

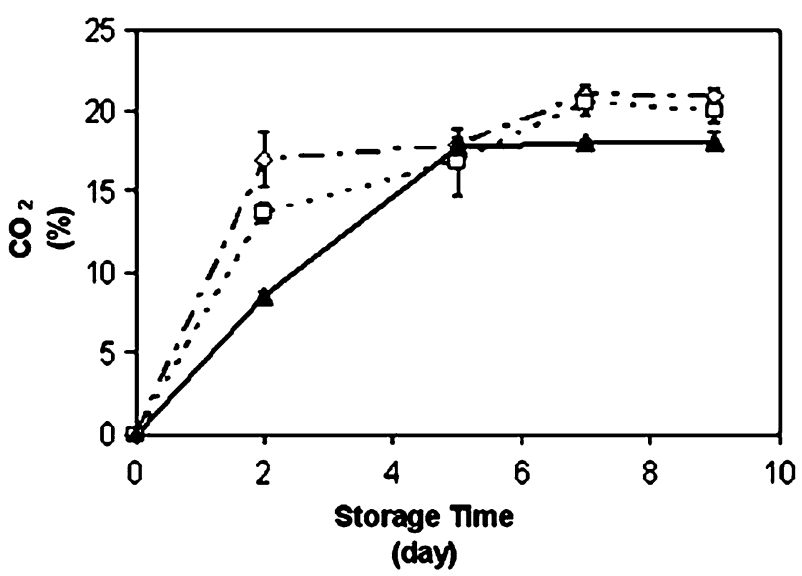

Fig. $1 \mathrm{CO}_{2}$ headspace composition of minimally processed kiwifruit packaging during storage. Open diamond $45^{\circ} \mathrm{C} / 25 \mathrm{~min}$; open square $45^{\circ} \mathrm{C} / 75 \mathrm{~min}$; filled triangle Control. Each data point represents mean $\pm \mathrm{SE}$

respectively. From the fifth day to the end of storage period the concentration of $\mathrm{CO}_{2}$ inside the packaging was similar for treated and control fruits (c.a. 19\%). Paull and Chen [16] refer that the respiration rate of ripening fruit is initially increased by exposure to higher temperatures but, after treatment the respiration rate declines to near or below the level of nonheated control. In minimally processed kiwifruit a similar pattern was found between heat-treated and control samples.

The accumulation of $\mathrm{CO}_{2}$ was followed by depletion in $\mathrm{O}_{2}$ levels, reaching about $4.5 \%$ of $\mathrm{O}_{2}$ inside packages of all samples at the end of storage period.

Changes in respiration rate as a result of whole fruit heat treatments and/or minimal processing operations were observed in sweet cherry [26], cantaloupe melon [4], peaches [27], plums [28] apples [29, 30] and pears [31] among others, depending besides other factors on cultivar, maturity stage, age of tissue and storage temperature [16]. In our work, we notice that the effect of the minimal processing operations on respiratory activity of kiwifruit could not be minimized by the application of moderate heat pre-treatments.
The tolerance of minimally processed products to low $\mathrm{O}_{2}$ and high $\mathrm{CO}_{2}$ levels depends upon the commodity. Low levels of $\mathrm{O}_{2}$ combined with high concentration of $\mathrm{CO}_{2}$ may induce fermentative reactions with the production of ethanol and acetaldehyde imparting off-flavours.

The $\mathrm{O}_{2}$ level can be allowed to drop to near or at the respiratory quotient breakpoint, the $\mathrm{O}_{2}$ concentration which corresponds to a sudden raise of the respiratory coefficient [32], without injury [33].

Some works [8] refer that $\mathrm{O}_{2}$ levels below $0.5 \%$ can enhance the production of acetaldehyde and ethanol, while modified atmospheres with $2-4 \mathrm{kPa} \mathrm{O}_{2}$ and/or 5$10 \mathrm{kPa} \mathrm{CO}_{2}$, in combination with calcium treatments, were effective in maintaining the quality of fresh-cut kiwifruit slices for 9-12 days. In minimally processed pineapple wedges no off-odour or off-flavours were detected after a 2-week storage period, at $\mathrm{O}_{2}$ and $\mathrm{CO}_{2}$ levels lower than $2 \%$ and higher than $15 \%$, respectively [34].

In the present work, the $\mathrm{O}_{2}$ concentrations inside packaging never drops below the referred levels.

Samples' pericarp colour evolution during a 9-day storage period is summarized in Table 2. The major changes occurred in the first 2 days of storage. Samples' $\mathrm{L}^{*}$ and $c$ underwent a decline indicating some yellowing resulting from chlorophyll degradation. These changes were mainly due to minimal processing, as followed by control as well, and were marginally affected by heat treatments. Cut surface browning was not noticed. Hue angle, the parameter that better describes the human eye perception of colour, underwent marginal differences in all samples along the whole storage period; hence, these changes were not visually perceptible.

These results are in accordance with previous results [12] in which the adjusted model showed a similar pattern of evolution of $\mathrm{L}^{*}$ value for firm ripe kiwifruit.

Loss of kiwifruit's pericarp green colour, yielding an increase in $a^{*}$ values, and induced by cutting had already been observed, probably due to chlorophyll degradation and consequently to pheophytin forma- 
Table 3 Colour of minimally processed kiwifruits' white core during storage

\begin{tabular}{|c|c|c|c|c|c|c|c|c|c|}
\hline \multirow{2}{*}{$\begin{array}{l}\text { Storage } \\
\text { time (day) }\end{array}$} & \multicolumn{3}{|c|}{$45^{\circ} \mathrm{C} / 25 \mathrm{~min}$} & \multicolumn{3}{|c|}{$45^{\circ} \mathrm{C} / 75 \mathrm{~min}$} & \multicolumn{3}{|l|}{ Control } \\
\hline & $\mathrm{L}$ & $c$ & $h$ & $\mathrm{~L}$ & $c$ & $h$ & $\mathrm{~L}$ & $c$ & $h$ \\
\hline 0 & $65.10^{\mathrm{a}}$ & $20.65^{\mathrm{b}}$ & $109.24^{\mathrm{a}}$ & $65.21^{\mathrm{a}}$ & $19.88^{\mathrm{bc}}$ & $108.09^{\mathrm{a}}$ & $67.93^{\mathrm{a}}$ & $23.27^{\mathrm{a}}$ & $108.38^{\mathrm{a}}$ \\
\hline 2 & $60.96^{\mathrm{b}}$ & $19.82^{\mathrm{bc}}$ & $105.58^{\mathrm{bc}}$ & $58.14^{\text {bcde }}$ & $18.67^{\mathrm{bcd}}$ & $105.04^{\mathrm{bc}}$ & $58.62^{\text {bcde }}$ & $19.28^{\mathrm{bcd}}$ & $106.25^{\mathrm{b}}$ \\
\hline 5 & $60.32^{b c}$ & $17.98^{\text {cde }}$ & $103.32^{\text {de }}$ & $59.01^{\text {bcde }}$ & $19.26^{\mathrm{bcd}}$ & $102.73^{\text {ef }}$ & $59.87^{\text {bcd }}$ & $19.66^{\mathrm{bcd}}$ & $105.06^{\mathrm{bc}}$ \\
\hline 7 & $57.20^{\text {cde }}$ & $18.52^{\text {bcde }}$ & $102.81^{\text {ef }}$ & $56.68^{\mathrm{de}}$ & $17.55^{\mathrm{de}}$ & $102.29^{\text {ef }}$ & $60.06^{\mathrm{bc}}$ & $18.43^{\text {bcde }}$ & $104.47^{\mathrm{cd}}$ \\
\hline 9 & $59.66^{\text {bcde }}$ & $18.16^{\text {cde }}$ & $101.78^{\mathrm{f}}$ & $58.62^{\text {bcde }}$ & $18.20^{\text {cde }}$ & $101.72^{\mathrm{f}}$ & $56.52^{\mathrm{e}}$ & $16.48^{\mathrm{e}}$ & $102.91^{\mathrm{ef}}$ \\
\hline
\end{tabular}

For each colour parameter values followed by the same lowercase letter are not significantly different at $P<0.01$, Fisher LSD test

tion [35]. Blanching treatments at $99.8^{\circ} \mathrm{C}$ for periods longer than $5 \mathrm{~min}$ also lead to an increase in a* values of outer pericarp tissue of kiwifruit halves [36]. Rocculi et al. [9] observed similar colour changes in minimally processed kiwifruit, $c$ being the most affected parameter. The authors conclude that a storage atmosphere of $90 \% \mathrm{~N}_{2} \mathrm{O}, 5 \% \mathrm{O}_{2}$ and $5 \%$ of $\mathrm{CO}_{2}$ allowed a better preservation of $\mathrm{L}^{*}$ and $h^{\circ}$, probably due to an indirect inhibitory effect of clorophyllase by $\mathrm{N}_{2} \mathrm{O}$. Nevertheless, other authors referred that there did not appear to be any consistent relationship between the changes occurred in the total chlorophyll content (degraded between 70 and $80 \%$ ) and colour of kiwifruit slices subjected to blanching and vacuum solutes impregnation [37]. Agar et al. [8] report a slight brown discolouration in slices exposed to $10 \mathrm{kPa}$ or higher of $\mathrm{CO}_{2}$ but this effect was observed just in 1 year experiment, not being confirmed in the second one. On the other hand, the same authors state that kiwifruit slices' surface darkening, expressed by a decreased $L^{*}$ value, was due to the induction of a translucent water soaked tissue and not to enzymatic browning.

Colour was also measured in the white core of slices (Table 3). In parallel with the pericarp, heat treatments only marginally affect slices colour. The observed differences were mainly due to minimal processing as both treated and control samples underwent the same colour evolution. Chroma was the only parameter slightly affected by heat treatments. Despite the fact that at the beginning of the storage period treated samples showed lower $c$ values than control, from the second day onwards the three samples did not show significant differences $(P>0.01)$. Limited information is available about colour changes of kiwifruits' white core. Rocculi et al. [9] measured colour changes of kiwifruit white core by image analysis and conclude that just a modified atmosphere with $\mathrm{N}_{2} \mathrm{O}$ could minimize the occurrence of brown area, which represented more than $90 \%$ in control after 4 days. In our work, colour was evaluated both by the tristimulus reflectance method and by sensory analysis but such noticeable changes were not detected.

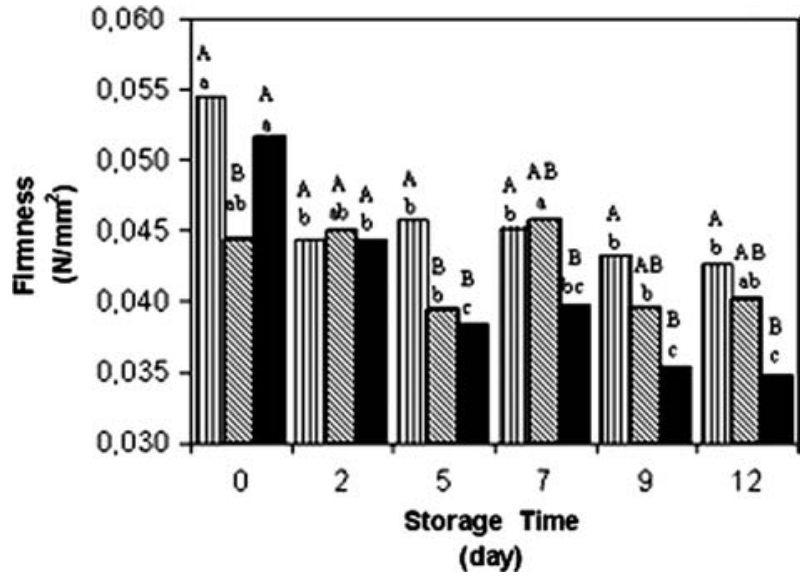

Fig. 2 Effect of heat treatment and storage time on firmness of minimally processed kiwifruit during storage. Above each bar, different uppercase indicate significant differences at each time for different samples, while different lowercase indicate significant differences of each sample at different times (Fisher LSD). Bar with vertical lines $45^{\circ} \mathrm{C} / 25 \mathrm{~min}$; bar with slanting lines $45^{\circ} \mathrm{C} /$ 75 min; filled bar Control

The influence of the application of mild heat treatments in kiwifruit firmness is shown in Fig. 2.

It is apparent that all samples evidenced a gradual softening along the 12-day storage period. Nevertheless, in control samples, the firmness decrease was more pronounced than in treated samples. Immediately after minimal processing, samples treated at $45{ }^{\circ} \mathrm{C}$ during 75 min showed a lower firmness $(\approx 15 \%)$ than the other two, but this value was almost constant until the end of the storage period. At the second day of storage no significant differences were found between the three samples. After 5 days, control samples continued evidencing a faster softening pattern while samples subjected to treatment at $45^{\circ} \mathrm{C} / 25 \mathrm{~min}$ preserve the firmness of the second day of storage. After 12 days of storage, control samples showed a reduction of firmness of about $49 \%$ while samples treated at $45{ }^{\circ} \mathrm{C} / 25 \mathrm{~min}$ exhibit a softening of $22 \%$, in comparison with the raw material.

Firmness is the most limiting parameter in quality maintenance of kiwifruit slices. Agar et al. [8] conclude 
that the hurdle effects of storage temperature, ethylene scrubbing, calcium treatments and modified atmosphere, could minimize kiwifruit softening. However, even the most effective treatments used lead to a decline in firmness values between 25 and $50 \%$ of initial raw material. Rocculi et al. [9] also describe positive effects on firmness preservation of kiwifruit slices by packaging atmospheres with argon or nitrous oxide. Slices underwent a firmness decrease about $10 \%$ after 8 days of storage and a $36 \%$ decrease after 12 days. As pre-treatment, the application of 1-MCP to whole kiwifruit results in a firmness decrease of just $12.5 \%$ in fruit halves, after 10 days of storage [35].

The firming effect of moderate heat pre-treatments in kiwifruit slices had already been observed in previous work [12], and it was supposed that the preservation of firmness was due to the activation of pectin methylesterase (PME) (EC 3.1.1.11) and subsequent formation of calcium pectates. In our results, the analysis of pectic polymers (Fig. 3) and free and linked calcium (Fig. 4) support this hypothesis. In control samples, the period of faster softening was accompanied by a marked increase in soluble pectin content. From the fifth day and until the end of storage, the level of those polysaccharides remained constant but tissue softening proceeds. In heat-treated samples, the levels of soluble pectin remain constant during the same period. Samples heated during $75 \mathrm{~min}$ showed at the beginning a higher level of soluble pectin, explaining the lower firmness, but this value was maintained until the end of storage. The prolonged heat treatment promotes the release of strongly linked polysaccharides; therefore, this sample also exhibits higher content of total pectin, at the beginning of storage (Fig. 4).

In samples treated during $25 \mathrm{~min}$, soluble pectin just began to increase after 5 days storage. Despite the differences observed in firmness, at the end of storage, all samples showed similar levels of soluble pectin.

Varoquaux et al. [6] already suggested that the texture breakdown of kiwi slices is probably due to enzyme catalysed hydrolysis of cell wall components.

One day after heat treatments, both treated samples showed similar levels of free calcium, about 7-9\% lower than control samples, suggesting that in heat treatments of samples calcium pectates formation occurred.

At the end of 9 days packaging all samples showed similar levels of free calcium. During the storage period the progressive PME activity induced by slicing allows, in control samples, the formation of calcium pectates as well. Nevertheless, this slower process was superseded by a faster and stronger softening of samples as observed.
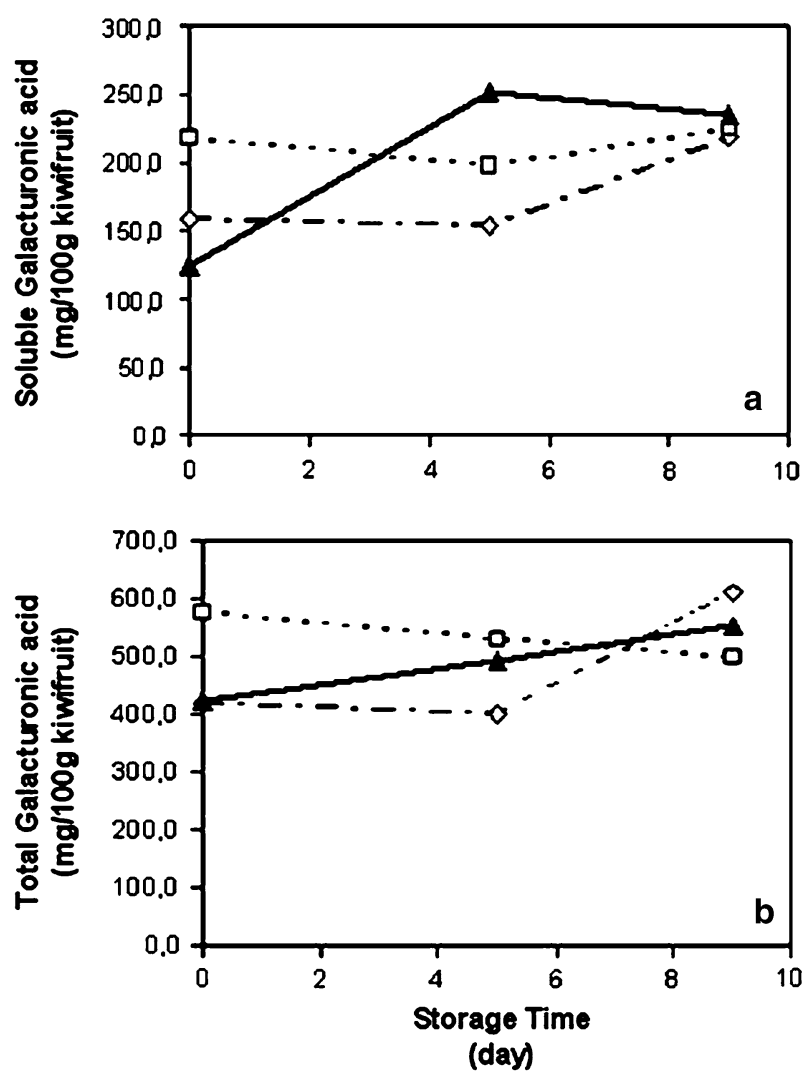

Fig. 3 Effect of heat treatment and storage time on (a) soluble galacturonic acid and (b) total galacturonic acid of minimally processed kiwifruit during storage. Open diamond $45^{\circ} \mathrm{C} / 25 \mathrm{~min}$; open square $45^{\circ} \mathrm{C} / 75 \mathrm{~min}$; filled triangle control

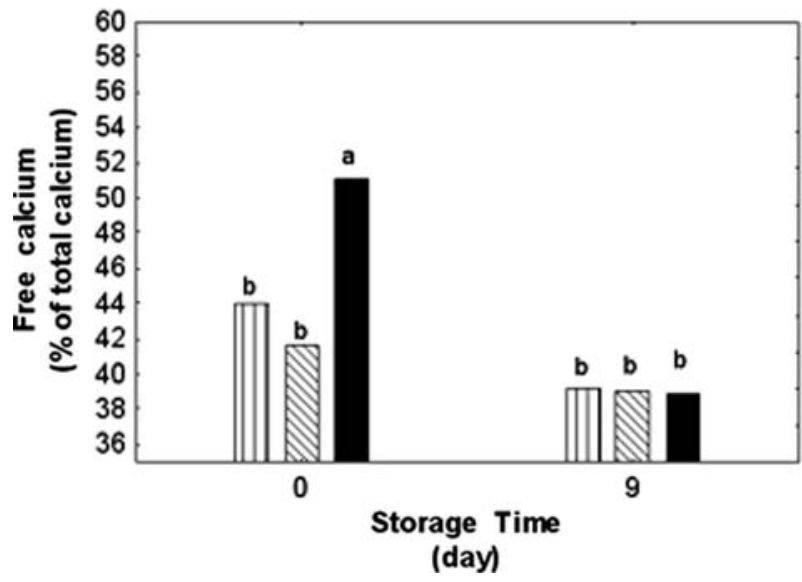

Fig. 4 Free calcium (\% of the total calcium in samples) of minimally processed kiwifruit. Bars with the same lower case are not significant different at $95 \%$. Bar with vertical lines $45^{\circ} \mathrm{C} / 25 \mathrm{~min}$; Bar with slanting lines $45^{\circ} \mathrm{C} / 75 \mathrm{~min}$; filled bar control

Despite the fact that PME activity was not measured during and after the heat treatments, the results seem to prove that those heat treatments promote PME activation allowing cross linking between endogenous 
calcium and demethylated galacturonic acid chains from pectin polymers in the cell wall and middle lamella.

Zhang and Chen [38] showed that soaking treatments influence the texture of green eggplants and optimum results were obtained at $52.6{ }^{\circ} \mathrm{C}$ for $18.9 \mathrm{~min}$ in $\mathrm{NaCl}$ solution at $0.224 \mathrm{~mol} / \mathrm{dm}^{3}$. In eggplants, a progressive activation of PME was clear between $30^{\circ} \mathrm{C}$ and $65^{\circ} \mathrm{C}$, but the enzyme was stable at $50^{\circ} \mathrm{C}$ for $20 \mathrm{~min}$. When incubated at $60^{\circ} \mathrm{C}$, the residual activity decreased significantly during the first $10 \mathrm{~min}$ of incubation, but the residual activity decreased slightly as incubation time progressed, perhaps due to different isoforms of PME present, with different thermal resistances.

Vicente et al. [39] refer that air heat treatments at $45^{\circ} \mathrm{C}$ for $3 \mathrm{~h}$ delay strawberries' softening by enhancing PME activity, diminishing endo-1,4- $\beta$-D-glucanase, $\beta$-xylosidase, $\beta$-galactosidase and polygalacturonase activities, delaying hemicellulose degradation and pectin solubilization.

Luna-Guzmán et al. [17] describe as well, for cantaloupe melon, the firming effect of heat treatments at 20, 40 and $60{ }^{\circ} \mathrm{C}$ in association with dips in $2.5 \%$ calcium chloride solutions and, therefore it may be possible that the observed effect in kiwi slices quality maintenance could be enhanced by the application of calcium.

Fructose and glucose were the main sugars in analysed kiwifruit (Fig. 5). Fructose $(\approx 53 \%)$ was present in slightly larger amounts than glucose $(\approx 38 \%)$. Sucrose is also present but at lower levels $(\approx 9 \%)$. Other authors $[8,10,40]$ refer a similar relation between these different sugars found in kiwifruit. Both heattreated samples showed higher $(P<0.05)$ levels of sucrose than control samples that retain the initial content of sucrose during all storage period, indicating that this enhancement was due to heat treatment rather than to minimal processing.

Despite the results demonstration of a clear connection between heat treatment and sucrose content increase, the mechanisms involved are somewhat unknown. The hydrolysis of larger polysaccharides by the heat treatments is a possibility which should be considered. On the other hand, the activation of enzymes responsible for sucrose synthesis, like sucrose phosphate synthase (SPS) and sucrose synthase, as response to stress imposed by heat treatment is also possible. The activity of these enzymes barely changes before and during the period of rapid sugar increase but it is known that a competition between sucrose synthesis and degradation exists during postharvest ripening [41. Langenkämper et al. [42] report that SPS mRNA increases in kiwifruit in response to ethylene. It is possible that heat
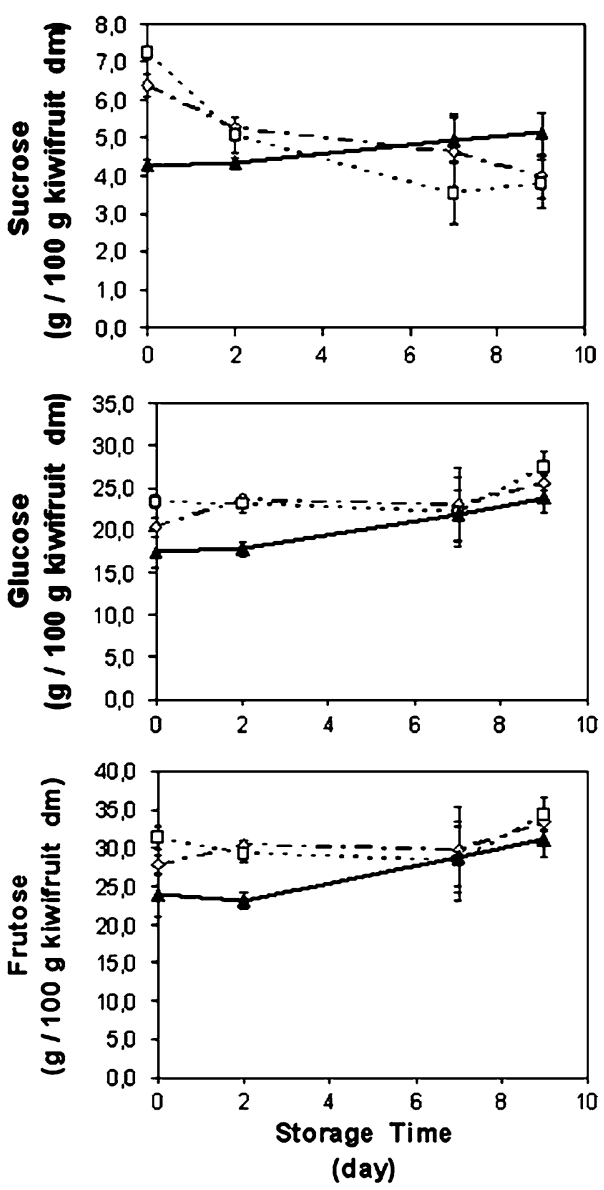

Fig. 5 Effect of heat treatment and storage time on sugars content of minimally processed kiwifruit during storage. Open diamond $45^{\circ} \mathrm{C} / 25 \mathrm{~min}$; Open square $45^{\circ} \mathrm{C} / 75 \mathrm{~min}$; filled triangle control. Each data point represents mean \pm SE. Bars not revealed are hidden with symbols

treatment led to a higher production of ethylene, contributing as well to sucrose synthesis.

In the first 2 days both samples exhibit a decline in sucrose concentration, to levels similar to control. As fructose and glucose concentration remained identical in the same period, the assumption of disaccharide hydrolysis is improbable. As already observed, heat treatments lead to a rise in respiration rate, confirmed by the greater accumulation of $\mathrm{CO}_{2}$ inside packages. The decline in sucrose level may suggest that this sugar was consumed as respiration substrate.

In control samples glucose and fructose content increased $(P<0.05)$ from day 7 , revealing the occurrence of hydrolysis, but sucrose content remained at the same, probably due to continued ripening.

The acids analysed in samples were quinic, citric, malic and ascorbic (Fig. 6). Quinic acid is the one present in major amount $(\approx 53 \%)$ followed by citric acid $(\approx 42 \%)$. L-malic acid is present in about $2 \%$ of the total acid amount and L-ascorbic acid, the most active 
Fig. 6 Effect of heat treatment and storage time on acids content of minimally processed kiwifruit during storage. Open diamond $45^{\circ} \mathrm{C} /$ $25 \mathrm{~min}$; open square $45^{\circ} \mathrm{Cl}$ $75 \mathrm{~min}$, filled triangle control. Each data point represents mean \pm SE. Bars not revealed are hidden with symbols
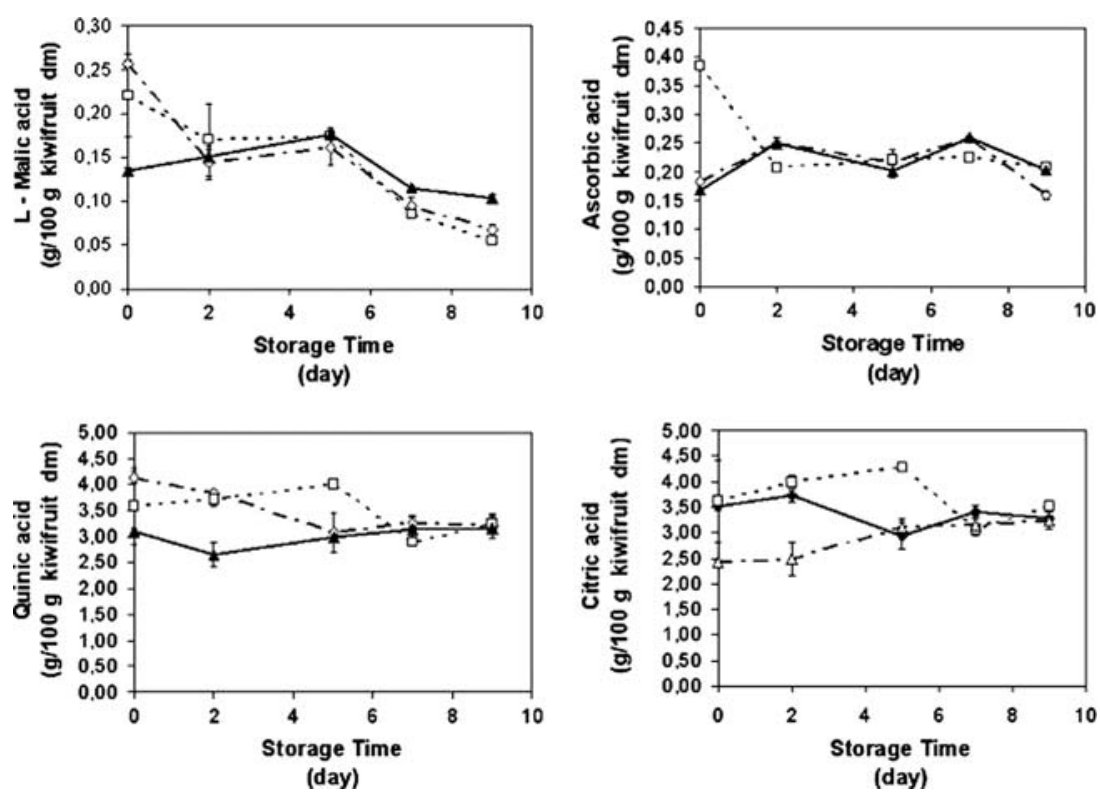

form of vitamin C [43], represents about $3 \%$ of total acids.

Some authors have referred different levels of these acids in kiwifruit $[8,10,44]$. The nutrient content of fruits is subject to variation within a species but there are also differences due to environmental and cultural practices [45, 46]. Storage temperature of whole fruit can change the balance of quinic, citric and L-malic acids in the fruit [44].

Heat-treated samples showed higher levels of all analysed organic acids, at the beginning of the storage period.

As consequence of minimal processing, L-malic acid content decreases during the first two storage days, which may be due to the more pronounced respiratory activity for heat-treated fruits. Afterwards, the three samples showed a progressive decrease but with no significant $(P>0.05)$ differences between each other.

Citric acid contents were higher $(P<0.05)$ than control in samples treated, respectively, during $25 \mathrm{~min}$ and $75 \mathrm{~min}$, for 2 and 5 days. Thereafter, all samples maintained equal and unchanged values until the end of storage. A similar pattern was found for quinic acid. As quinic acid is the one responsible for the "Hayward" flavour [44], the maintenance/increment of its content may be desirable for the maintenance of flavour profile during storage.

For both of these acids, control samples evidenced no significant differences $(P>0.05)$ during storage. At the end of the storage period, acids levels are similar for all samples.

The stress imposed by minimal processing led to ascorbic acid synthesis, which is confirmed by the significant $(P<0.05)$ increase in its content in samples at the second day of storage. The antioxidant role played by L-ascorbic acid is what makes this small molecule a crucial component of the plant response to different stress agents [47]. The marked increased observed in samples treated at $45^{\circ} \mathrm{C} / 75 \mathrm{~min}$ was due to the higher stress caused by a longer heat treatment. All recent publications seem to indicate that multiple L-ascorbic acid biosynthetic pathways are functioning in plants. However, definitive proof of their occurrence must be obtained either by using quantitative radiolabelling studies or by reverse genetics [48]. Nevertheless, sample heat-treated for $75 \mathrm{~min}$ showed higher soluble pectin content, as can be seen in Fig. 3. It is known that D-galacturonic acid is metabolized to L-ascorbic acid6-14C by an inversion pathway in detached ripening strawberry fruit. In this pathway, pectin-derived Dgalacturonic acid is reduced to L-galactonic acid, which in turn is spontaneously converted to L-galactono- 1,4 lactone. This compound is the substrate of the L-galactono-1,4-lactone dehydrogenase enzyme, producing Lascorbic acid [48].

However, the benefit of the treatment from nutritional point of view was lost, since from the second day the vitamin content drops to level similar to other samples. Despite the higher levels of $\mathrm{CO}_{2}$ inside packages, from that moment and until the end of storage, ascorbic acid content was maintained in all samples. The stability of ascorbic acid in kiwifruit slices can be partially justified by the $\mathrm{pH}$ of the fruit [45].

Our results are in agreement with others for citrus segments [49], cactus pear [50] and Golden delicious apples [51] in which ascorbic acid content was marginally affected by minimal processing, but not with those of [8] that report a total ascorbic acid progressive loss 


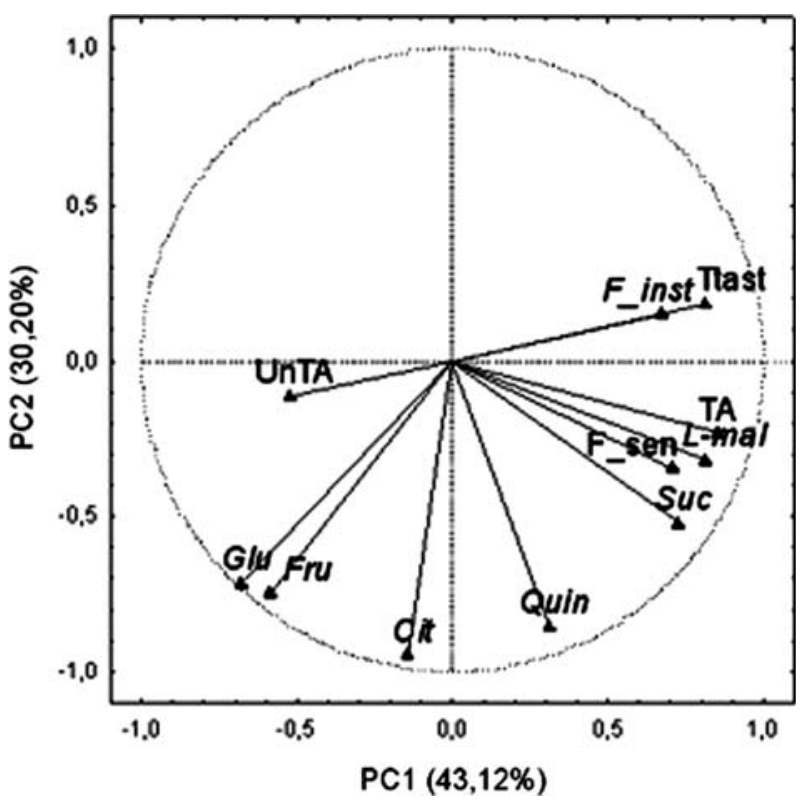

Fig. 7 Principal components comparison of variables: aromatypical $(T A)$ and untypical (UnTA), typical taste (Ttast), firmness-sensorial ( $F \_$sen) and instrumental $\left(F \_\right.$inst), and chemical composition-glucose $(G l u)$, fructose $(F r u)$, sucrose $(S u c)$, citric acid (Cit), L-malic acid (L-mal) and quinic acid (Quin)

for kiwifruit slices during 12 days of storage, either packed in air or under various modified atmosphere packaging. Ferguson and Macrae [52] reported that the content in total ascorbic acid in Actinidea fruits, including Actinidea deliciosa, showed little or no decline during postharvest ripening.

The effect of heat treatments in ascorbic content is also ambiguous. The application of an air heat treatment of $50{ }^{\circ} \mathrm{C}$ for $2 \mathrm{~h}$ slowed the decrease in ascorbic acid content of broccoli florets [53], but the applications of air heat treatments at 34 and $38^{\circ} \mathrm{C}$ led to higher losses in ascorbic acid than for non-treated tomato fruits [54].

Principal components analysis allowed a better understanding of interactions between objective and sensorial measurements. The two first principal components (PC's) explained $73.32 \%$ of total variance. As can be seen in Fig. 7, there is a strong correlation between sensorial parameters of firmness, typical aroma and taste and objective measurements like firmness, sucrose and L-malic contents, all positively associated with the PC1. It can be stated that these objective measurements are related to freshness attributes.

After the observed correlations a new analysis was performed using only the objective parameters data. The two first PC explained $84.02 \%$ of the total variance of the data. Nevertheless, firmness, a critical quality parameter in minimally processed kiwifruit, has a high

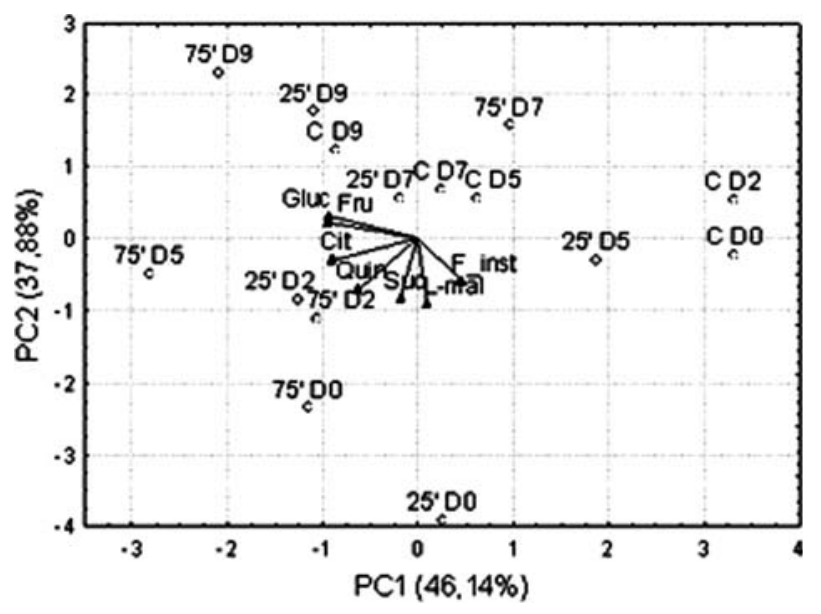

Fig. 8 Principal components comparison (PC1 vs. PC2) of firmness instrumental $\left(F \_\right.$inst $)$and chemical composition-glucose $(G l u)$, fructose $(F r u)$, sucrose $(S u c)$, citric acid (Cit), L-malic acid (L-mal) and quinic acid (Quin). Samples: heat-treated 25 and $75 \min \left(25^{\prime}, 75^{\prime}\right.$, respectively), control $(C) ; 0,2,5,9$ days of storage-D0,D2, D5, D9, respectively

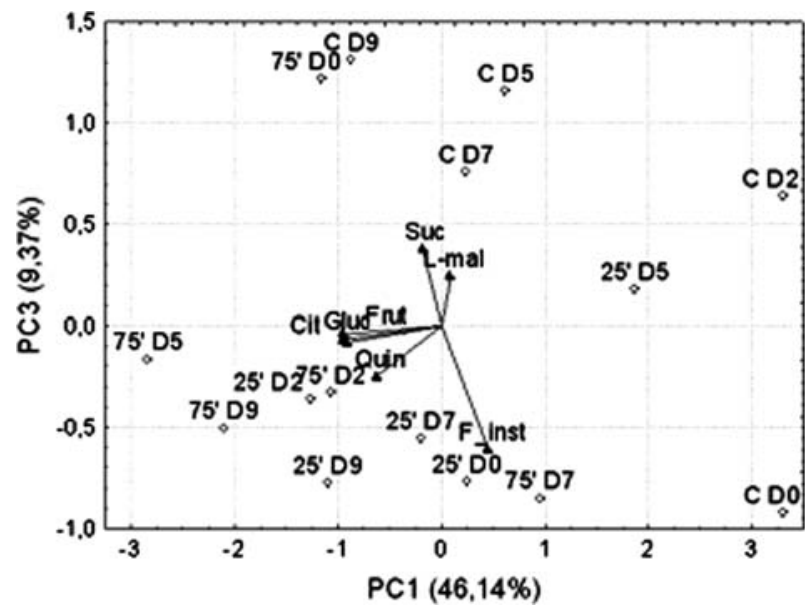

Fig. 9 Principal components comparison (PC1 vs. PC3) of firmness instrumental ( $F \_$inst $)$and chemical composition-glucose $(\mathrm{Glu})$, fructose $(\mathrm{Fru})$, sucrose $(\mathrm{Suc})$, citric acid (Cit), L-malic acid (L-mal) and quinic acid (Quin). Samples: heat-treated 25 and 75 min $\left(25^{\prime}, 75^{\prime}\right.$, respectively), control $(C) ; 0,2,5,9$ days of storage- $D 0, D 2, D 5, D 9$, respectively

correlation with PC3 $(9.37 \%)$, and therefore can be useful in samples' differentiation. Figures 8 and 9 show the projection of analysed variables and samples in the space of PC1, PC2 and PC3.

From Fig. 8, it can be observed that samples from day seven onwards are correlated with higher concentration of simple sugars, denoting some polysaccharide hydrolysis. On the other hand, heat-treated samples, until the fifth day of storage, are correlated with higher content of quinic and citric acid maintaining the flavour of fresh fruit. The projection of PC also permits the 
confirmation that both heat treatments applied led to a better maintenance of firmness. In Fig. 9, the correlation of the heat-treated samples during almost all storage periods with firmness is apparent.

\section{Conclusions}

Since softening is the crucial problem in sliced kiwifruit quality, the application of moderate heat pre-treatments to whole kiwis allowed firmness preservation of the minimally processed fruit. Despite the fact that both heat treatments maintained the saleable quality of minimally processed kiwifruit for 9 days at $4{ }^{\circ} \mathrm{C}$, treatment at $45^{\circ} \mathrm{C}$ for $25 \mathrm{~min}$ maintained a better quality of the commodity. The mechanism involved in the process was the formation of calcium pectates from demethylated galacturonic acid chains and endogenous calcium, enhanced by heat treatment. Significant ascorbic acid loss was not observed in sliced fruit. On the other side, it is noteworthy that an increment in this vitamin content was observed after heat treatment; it is nevertheless necessary to use supplementary techniques in order to preserve the concentration of biologically active compounds that tends to diminish.

Heat treatments at $45^{\circ} \mathrm{C}$ seem to be a "clean technology" useful in quality preservation of minimally processed kiwifruit.

Acknowledgments The first author acknowledges financial support from Fundação para a Ciência e Tecnologia, Portugal through programme POCTI.

\section{References}

1. Ragaert P, Verbeke W, Devlieghere F, Debevere J (2004) Food Qual Pref 15:259-270

2. Allende A, Tomás-Barberán FA, Gil I (2006) Trends Food Sci Technol 17:513-519

3. Gil MI, Aguayo E, Kader AA (2006) J Agric Food Chem 54:4284-4296

4. Lamikanra O, Bett-Garber KL, Ingram DA, Watson MA (2005) J Food Sci 70:C53-C57

5. Soliva-Fortuny RC, Martín-Belloso O (2003) Trends Food Sci Technol 14:341-353

6. Varoquaux P, Lecendre I, Varoquaux F, Souty M (1990) Sci Aliments 10:127-139

7. O'Connor-Shaw RE, Roberts R, Ford AL, Nottingham SM (1994) J Food Sci 59:1202-1206

8. Agar IT, Massantini R, Hess-Pierce B, Kader AA (1999) J Food Sci 64:433-440

9. Rocculi P, Romani S, Dalla Rosa M (2005) Postharvest Biol Technol 35:319-328

10. Wang CY, Buta JG (2003) Postharvest Biol Technol 28:181186

11. Colelli G, Amodio ML, Natola K (2004) Ind Alimentari 43:382-388, 392
12. Beirão-da-Costa S, Steiner A, Correia L, Empis J, MoldãoMartins M (2006) J Food Eng 76:616-625

13. Malakou A, Nanos GD (2005) Postharvest Biol Technol 38:106-114

14. Ni L, Lin D, Barrett DM (2005) J Food Eng 70:546-556

15. Falik E (2004) Postharvest Biol Technol 32:125-134

16. Paull RE, Chen NJ (2000) Postharvest Biol Technol 21:21-37

17. Luna-Guzmán I, Cantwell M, Barrett DM (1999) Postharvest Biol Technol 17:201-213

18. Abreu M, Beirão-da-Costa S, Gonçalves EM, Beirão-da-Costa ML, Moldão-Martins M (2003) Postharvest Biol Technol 30:153-160

19. Kim DM, Smith NL, Lee CY (1993) J Food Sci 58:11111124

20. Plotto A, Bai J, Narciso JA, Brecht JK, Baldwin EA (2006) Postharvest Biol Technol 39:134-145

21. Crisosto CH, Kader AA (1999) http://www.uckac.edu/postharv/PDF \%20files/Guidelines/kiwi.pdf\#search = \%22carlos $\% 20$ crisosto $\% 22$

22. McGuire RG (1992) HortScience 27:1254-1255

23. Medlicott AP,1 Thompson AK (1985) J Sci Food Agric 36:561-566

24. Romero-Rodriguez A, Oderiz LV, Hernandez Jl, Simal Gandar J (1992) Sci Aliments 12:593-600

25. NF V05-128 (1984) Fruits, Légumes et Produits dérivés. Détermination des substances pectiques

26. Alique R, Zamorano JP, Martinez MA, Alonso J (2005) Postharvest Biol Technol 35:153-165

27. Steiner A, Correia L, Beirão-da-Costa S, Leitão E, Beirãoda-Costa ML, Empis J, Moldão-Martins M (2006) Eur Food Res Technol 222:217-222

28. Serrano M, Martínez-Romero D, Castillo S, Guillén F, Valero D (2004) Postharvest Biol Technol 34:155-167

29. Rocculi P, Romani S, Dalla Rosa M (2004) Food Res Int 37:329-335

30. Rocculi P, Del Nobile MA, Romani S, Baiano A, Dalla Rosa M (2006) J Food Eng 76:334-340

31. Soliva-Fortuny RC, Biosca-Biosca M, Grigelmo-Miguel N, Martín-Belloso O (2002) J Sci Food Agric 82:1490-1496

32. Gran CD, Beaudry RM (1993) Postharvest Biol Technol 3:259-267

33. Watada AE, Qi L (1999) Postharvest Biol Technol 15:201205

34. Marrero A, Kader AA (2001) Acta Hort 553:705-706

35. Mao L, Wang G, Que F (2007) J Food Eng 78:361-365

36. Llano KM, Haedo AS, Gerschenson LN, Rojas AM (2003) Food Res Int 36:767-775

37. Leunda MA, Guerrero SN, Alzamora SM (2000) J Food Proc Pres 24:17-38

38. Zhang M, Chen D (2006) J Food Eng 74:54-59

39. Vicente AR, Costa ML, Martínez GA, Chaves AR, Civello PM (2005) Postharvest Biol Technol 38:213-222

40. Marsh KB, Friel EN, Gunson A, Lund C, MacRae E (2006) Food Qual Pref 17:376-386

41. Cheah LH, Irving DE (1997) Kiwifruit. In: Mitra SK (ed) Postharvest physiology and storage of tropical and subtropical fruits. Cab International, Wallingford, pp 209-227

42. Langenkämper G, McHale R, Gardner RC, MacRae E (1998) Plant Mol Biol 36:857-869

43. Nishiyama I, Amashitay Y, Yamanaka M, Shimohashi A, Fukuda T, Oota T (2004) J Agric Food Chem 52:5472-5475

44. Marsh K, Attanayake S, Walker S, Gunson A, Boldingh H, MacRae E (2004) Postharvest Biol Technol 32:159-168

45. Davey MW, Montagu MV, Inzé D, Sanmartin M, Kanellis A, Smirnoff N, Benzie IJJ, Strain JJ, Favell D, Fletcher J (2000) J Sci Food Agric 80:825-860 
46. Lee SK, Kader AA (2000) Postharvest Biol Technol 20:207220

47. Conklin PL, Barth C (2004) Plant Cell Environ 27:959-970

48. Valpuesta V, Botella MA (2004) Trends Plant Sci 9:573-577

49. Del Caro A, Piga A, Vacca V, Agabbio M (2004) Food Chem 84:99-105

50. Piga A, Del Caro A, Pinna I, Agabbio M (2003) Lebensm Wiss Technol 36:257-262
51. Cocci E, Rocculi P, Romani S, Dalla Rosa M (2006) Postharvest Biol Technol 39:265-271

52. Ferguson AR, MacRae EA (1991) Acta Hort 297:481-488

53. Shigenaga T, Yamauchi N, Funamoto Y, Shigyo M (2005) Postharvest Biol Technol 38:152-159

54. Soto-Zamora G, Yahia EM, Brecht JK, Gardea A (2005) Lebensm Wiss Technol 38:657-663 